\title{
Study of College Students' Environmental Awareness Cultivation Under the View of Ecological Civilization
}

\author{
Jie $\mathrm{He}^{1, \mathrm{a}}$ \\ ${ }^{1}$ Tianjin Vocational Institute, Tianjin 300410, China \\ ahejie1965@126.com
}

\begin{abstract}
Keywords: Environmental education. Ecological civilization. Environmental awareness. Method of cultivation

Abstract. In this article, the author analyzed the present situation of environmental education and environmental awareness cultivation in both China and the world, expounded the importance of college students' environmental awareness cultivation and presented the method to cultivate college students' environmental awareness under the view of ecological civilization.
\end{abstract}

\section{Introduction}

In the 17th National Congress of the CPC, a new idea of ecological civilization was presented. In the 18th National Congress of the CPC, the construction of ecological civilization was included in five-in-one overall arrangement for the cause of socialism with Chinese characteristics. In the third plenary session of the 18th CPC Central Committee, it was emphasized that we need to speed up the establishment of ecological civilization system and promote the formation of a harmonious development of human and nature of the new pattern of modernization, around the center of construction of beautiful China and deepen the reform of ecological civilization system. Ecological civilization is a new form of human civilization. With the premise of respecting and protecting nature the premise; the purpose of establishing the harmony between human and human, human and nature, human and social, and the content ofestablishing the sustainable development mode of production and the way of life, ecological civilization leads people to develop continuously and harmoniously. To establish ecological civilization, we should set up the idea of ecological civilization of respecting, protecting and complying with nature as the value,put the construction of ecological civilization in a prominent position and every aspects and all processes of the construction of economy, politics, culture and society, construct beautiful China and realize the sustainable development of the Chinese nation, and adhere to the basic state policy of conserving resources and protecting the environment. Strengthening college students' environmental education, cultivating and improvingcollege students' environmental awareness, and establishing the idea of ecological civilization of respecting, protecting and complying with nature are basic requirements to promote the construction of ecological civilization, as well as the important content of cultivating talents of college students.

\section{The present situation of environmental education and environmental awareness cultivation in both China and the world}

Environmental problems relate to the politics, economy, science, technology, culture, etc. of the society. We should cultivate college students' environmental awareness in multiple ways. Environmental education is a huge systematic project. The term "environmental education" was first used by Scottish botanist, Patrick GeddeS(1854-1933) in 1920 by putting "environment" and "education" in parallel. Internationally, it was used in the United Nations General Assembly in Paris in 1948 for the first time. Nowadays, the most important thing in environmental education is not only cognizing knowledge, but also emotional development. The general said environmental education is the environmental education to non-environmental specialty students. China mentioned the idea of environmental education for the first time in the first National Conference on Environmental Protection in 1973, which is a milestone of environmental education in this country. The Fourth National 
Conference on Environmental Protection in July, 1996 presented the thought - protecting the environment is protecting productivity, environmental awareness and quality is an important sign to evaluate the nation's civilization. After that, China's National Environmental Protection Bureau, Central Propaganda Department, and National Ministry of Education jointly issued the "National Environmental Education Action Plan". The "plan" pointed out that "Environmental education is the basic means to improve the ideological and moral quality, as well as scientific and cultural quality of the whole nation. It should be facing the 21th century, gradually improve China's environmental education system and further enhance the environmental awareness of the whole nation."

The practice of environmental education in foreign countries provides us with a lot of experience for reference and learning. For example, in Swedish Schools' environmental education, "sustainable development" is incorporated into all areas of study, and the environmental education has permeated all the subjects. German environmental education system emphasizes the unification of the government's compulsory and the citizen's consciousness, the unification of family education, school education and social education, the unification of innovation education and practical education to enhance the effectiveness of environmental education. Legislation and strict enforcement of environmental education is the successful experience of the United States. In the United States, environmental education institutions are sound andhave clear responsibilities, the investment channels of environmental education funds are diverse and stable, environmental education project management are strict.

Look at the environmental education in China, there are still many problems such as poor consciousness, lacking of awareness, lacking of investment, etc. The higher education in China has not been able to carry on the full environmental education to the majority of students, China hasn't valued the improvement of students' environmental awareness as an important foundation engineering of talents cultivation neither, so that environmental education in China is not normative and binding. Zhongyuan Chen published "Investigation on College Students' environmental awareness and Discussion on Environmental Education" on the second issue of "Exploration of higher education in Yunnan" in 1996, which was an earlier study on College Students' environmental awareness. From 1999, scholars have investigated the environmental awareness of college students in different regions and different majors. The objects included environmental specialized students from normal universities and non-environmental specialized students from non-normal universities. The result showed that the environmental awareness of college students in China was not good. The main problems were: knowing and doing were not synchronous, lacking of environmental practice and college students' environmental awareness had a strong dependence on the government. In the strategic study of improving College Students' environmental awareness, the scholars gave out some suggestions: placing environmental education in the university public courses and arranging environmental education activities in a planned way, adding environmental education courses in science and liberal arts majors, strengthening the construction of environmental courses, teaching staff and teaching materials, developing exchanges and cooperation, etc. The scholars had also conducted a micro study and a case study on how to improve the environmental education in classes to effectively improve the students' environmental awareness. They also pondered and discussed how to make college students' environmental awareness internalized and turn it to actions of environmental protection.

From the researches of environmental awareness, the amount of literature research on college students' environmental awareness was very uneven, but it has been increasing year by year since 1999 . In the current published articles, the researches on university students' environmental awareness are divided into qualitative researches and empirical researches and most of them are empirical researches. The empirical research articles are mainly based on the quantitative research methods, they emphasize on the data of the current situation of college students' environmental awareness, as well as the horizontal comparison of different groups of college students' environmental awareness; theoretical articles use qualitative research methods, focusing on the analysis and induction of the importance of environmental awareness education of college students and the empirical description of the 
improvement measures. Researches on the students' environmental awareness in the perspective of ecological civilization is a new topic for the students in higher vocational colleges in China.

\section{Significance of cultivating students' environmental awareness in higher vocational colleges}

Environmental awareness is the advanced concept of human thought and a new independent ideology. College students' environmental awareness is the main content of China's social environmental awareness, it has the basic content and the common characteristics of the social environmental awareness of China, as well as the particularity of college students. Because of the particularity of the subject, the environmental awareness of students in higher vocational colleges not only has common characteristics of that of college students in China, it also has its own characteristics with a wealth of content because it's more close to vocational field. Higher Vocational College Students' environmental awareness system mainly includes environmental science knowledge, environmental laws' awareness, environmental moral awareness and awareness of participation. Among them, the environmental science knowledge is the most important and the most basic element, it's also the foundation of environmental awareness; environmental laws' consciousness, also called the concept of environmental laws, is the central link of environmental awareness; good environmental moral consciousness is the highest level of environmental awareness; the awareness of participation is an extension of last three elements and is also the sense of responsibility of those who have the knowledge of environmental science and laws.

Higher vocational education is an important part of higher education in China. Higher vocational colleges shoulder the mission of training high quality skilled talents for production, construction, service and management and has an irreplaceable role in accelerating the construction of socialist modernization in China. As China's builders, policy makers and the owners of the environment in the future, higher vocational college students are important driving force of environmental protection and sustainable development. Their environmental awareness has a direct and realistic influence on environmental protection, which is closely related to the sustainable development of China. Higher vocational education started late in China, a multi-leveled, multi-formed and all-aspect environmental education system with the characteristics of higher vocational education has not been formed, and the source of students is complex. Totally speaking, higher vocational college students' environmental awareness is not high enough. The phenomena are: their understanding and grasping of environmental knowledge are superficial; their awareness of environmental protection is weak; they lack of a sense of responsibility for environmental protection; they lack of the motivation to protect the environment.

Environmental awareness is not only a kind of ideology, but also a demonstration of the idea of ecological civilization and the embodiment of a perfect personality.The goal of the construction of ecological civilization is to cultivate people who have the idea of ecological civilization, healthy body, independent personality and strong sense of social responsibility. Environmental awareness is one of the key factors to measure the quality of higher vocational college students, as well as the proper meaning of the construction of ecological civilization. As a result, it is important to study the cultivation of students' environmental awareness in higher vocational colleges based on the view of ecological civilization.

\section{The methods of cultivating students' environmental awareness in higher vocational colleges}

Let ideological and political theory courses play their roles on strengthening the education of students' environmental awareness. Ideological and political theory course is the main channel to strengthen the education of students' environmental awareness. Higher vocational colleges can't set up environmental education courses, so ideological and political theory course should be an important way to cultivate college students' environmental awareness. At present, the ideological and political theory coursesin higher vocational colleges mainly are: "An Introduction to Mao Zedong Thought and The Theory System of Socialism with Chinese Characteristics" (Hereinafter referred to as the 
"Introduction") and "The Basis of Ideological and Moral Cultivation and Law" (Hereinafter referred to as the "Basis").

In the courses, teachers can set up platforms of theoretical knowledge teaching and experience communication by combining the content and characteristics of the courses, and add the cultivation of College Students' environmental awareness in them. The core idea of environmental awareness is the relationship between man and nature environment. In the classic work of Marxism, the thoughts of the relationship between man and nature, as well as those of man and man has very deep meanings. We need to guide college students to establish the view of nature and value that human, nature and society are unified and harmonious, look from the long-term interests of human, realize the strategy of sustainable development and maintain the balance between economic development and environmental protection. These should be an important part of the course of the "Introduction".

Environmental ethics is a moral code of universal value in human society. It is a powerful spiritual power to protect the nature and build a good living environment. We should take environmental ethics, environmental laws and regulations as an important content in the "basic" course, guide the students to establish the moral consciousness and moral values of respecting the nature, and strengthen their environmental legal system concept and consciousness of obeying the law so that they can form a stable belief in environmental laws and regulations, consider the laws as the standards of their behaviors, and consciously behave under the legal constraints.

Taking the construction of cultural quality course as the carrier, and enrich the knowledge of environmental science. Cultural quality course is an important carrier to improve students' humanistic quality, it's also an important method to enrich students' knowledge of environmental science. Environmental science knowledge is the most important and basic element of environmental awareness. Higher vocational college students' knowledge of environment and environmental protection mainly includes: the knowledge of environmental issues, environment and development, ecology, environmental protection, environmental protection policies and regulations, energy using and etc. Cultural quality course about environmental setting and environmental protection based on the knowledge mentioned above can be developed. For example, the college in which the author is working, has developed and set many courses: "Introduction to environmental protection", "Environment and Health", "Chemistry and Society", "Chemistry and Life", "Chemistry and Modern Civilization", "Environmental Protection and Social Development"; "Introduction to Ecology", "Introduction to Life Science", "New Technology of Environmental Protection", "Low-carbon Economy", "Biotechnology and Human Society", "New Materials in Twenty-first Century", "Composite Materials Development and Human Life"; "Environmental Laws and Regulations"; "Status of China's Energy and Energy Conservation", "Energy and Society". All of these courses can be elected by the students in this college.

In the management of cultural quality courses, the college generally only require that each student must take a number of courses, the students select courses by themselves in each semester, so that the students are unlikely to choose many environmental and environmental protection courses while taking many other cultural quality course about literature, politics, economy, science and technology, environmental protection, etc. As a result, when developing environmental quality courses, we should not only focus on the development of courses in environmental and environmental protection, but also cover the most basic elements of the environment and environmental protection in each course. By doing this, the students can understand and absorb the knowledge of environmental science by taking one or more environmental cultural quality courses.

Make full use of internships in companies to strengthen the cultivation of environmental awareness. Quality education in higher vocational colleges is a kind of humanistic education in "professional form". Internships in companies provide an important platform to strengthen students' professional quality education and help to cultivate students' environmental awareness. The time spend to graduate from a higher vocational college is generally three years. With the spreading of the "working and learning" idea and project teaching, integrated teaching and internship teaching modes, the time spend in practical courses is increasing. When the students are practicing in companies, we 
should guide them to feel the real business atmosphere, understand the business culture, obey the rules of employee. Besides, we should introduce the environmental awareness training into students' internship process, and make the environmental education efficiency by giving them environmental project courses. Specific approaches are following. When preparation for the internship, the advisors should develop an internship environmental protection project book for the students according to their internship positions, and make some rules for them on environmental protection: understand the status of production and operation of the company, investigate and evaluate the environmental conditions of the company, make a summary of the experience that company got in environmental protection, find its problems in environmental protection and give out their own suggestions. The students should complete the plan of the environmental protection project. In the internship process, they should also submit the project reports and result reports according to the internship process. By exploring the implementation of environmental protection projects in the process of students' internship, the students can experience environmental protection and internalize environmental awareness in practicing. Cultivation of students' environmental awareness can also be evaluated.

Carry out kinds of social practice and promote the internalization and improvement of environmental awareness. Social practice is not only the best classroom for students to understand the national conditions and increase their abilities, but also an inevitable process for them to internalize the contents of environmental science and environmental education and turn them to environmental awareness. Social practice system contains a lot, Including student community activities, college students vacations and social practice, social survey, volunteer service and a variety of public benefit activities, etc. The association is an effective place for the cultivation of talents to higher vocational colleges. The environmental protection association has an irreplaceable role in the popularizing environmental protection knowledge and the improving students' environmental awareness, so the colleges should support them with human, material and financial resources. At the same time, environmental protection practice should be one of the social practice activities, and other association activities, if possible, should be relative to environmental protection.

Environmental awareness is the unification of "knowing" and "doing", and is finally reflected in the habits and behaviors of environmental protection. As a result, we need to guide the students to improve their weak environmental protection awareness and the disconnection of their environmental knowledge and environmental protection behaviors in varieties of social practice, and strengthen their sense of responsibility to protect the environment, and make sure of the unity of knowledge and practice.

\section{Combine with the construction of campus culture and stimulate environmental awareness in multiple ways.}

The campus culture quietly influences college students' ideology, value and behaviors, so the education combined with the construction of campus culture and the infiltration of environmental awareness is a very effective way. We should improve the construction of school newspapers, radios, televisions, windows and other publicity facilities, and give full play to them in environmental education. For example, during the world environment day, earth day, world water day, and world food day, strengthen the publicity and education of environmental knowledge and issues, and interiorize the thought of environmental protection. We can hold green campus activities such as "low-carbon month", "suggestions for low-carbon life", reducing the use of disposable items, competitions of environmental protection knowledge, speech contests and environmental lectures. We should also popularize environmental protection knowledge and cultivate good behavior habits of the students, expand environmental education and improve students' environmental moral consciousness. Add the elements of environmental protection into the teaching, training and living spaces of the campus, and promote the formation of students' environmental awareness quietly. 


\section{Acknowledgements}

This work was financially supported by the Tianjin 2015 philosophy and social science planning project (project Number: TJJX15-030).

\section{References}

[1] G.Q. Shi, Q. Zhong. Nanjing Social Sciences, (2009) No. 7. (In Chinese)

[2] G.H. Wang. Journal of Nantong University (Social Science), (2011) No. 1. (In Chinese)

[3] L. Li, L. Song. Psychological Science, (2014) No. 2. (In Chinese)

[4] M. Wang. Environmental Education, (2012) No. 12. (In Chinese)

[5] W.H Du, Z.L. Wang. Journal of Changchun Normal University, (2015) No. 4. (In Chinese)

[6] Y.C. Lin, X.Q. Mo, H.Y Li. Advanced Science Education, (2013) No. 6. (In Chinese)

[7] Q.M. Mao. Beijing Social Sciences, (2014) No. 5. (In Chinese) 